\title{
Redefining Employee Experience during the Pandemic
}

\author{
Juliet Shambi \\ Interactive Online Doctor of Business Administration, LIGS University, Honolulu, United States \\ Email: J.Shalis@gmail.com
}

How to cite this paper: Shambi, J. (2021). Redefining Employee Experience during the Pandemic. Journal of Human Resource and Sustainability Studies, 9, 434-438. https://doi.org/10.4236/jhrss.2021.93027

Received: June 25, 2021

Accepted: September 7, 2021

Published: September 10, 2021

Copyright $\odot 2021$ by author(s) and Scientific Research Publishing Inc. This work is licensed under the Creative Commons Attribution International License (CC BY 4.0).

http://creativecommons.org/licenses/by/4.0/

\begin{abstract}
COVID-19 has impacted the way organizations operate their businesses as well as how they interact with their workforce. Employee experience is no longer a HR buzz word, but it has become an important driver in productivity and engagement at the workplace. The paper aims at identifying employees' experiences during the pandemic and the approaches which the companies and managers have laid down to assist the employees during the period. More than ever, digital transformation has been an area where organizations are focusing on to ensure business continuity especially with a significant number of the world workforce working from home. The paper uses secondary data for in the analysis and analysis of existing studies to analyze the challenges affecting the employees' experiences.
\end{abstract}

\section{Keywords}

Employee, Experience, Transformation, Productivity, Well-Being

\section{Introduction}

Looking back on the effects of the pandemic, organizations have realized that for them to become agile and respond to both internal and external changes, there is need to embrace technology as an enabler of success. The crisis has become a fundamental change in driving employee related strategies especially in three areas: talent attraction and retention, employee productivity and engagement and employee well-being. A people centric business will be able to achieve and sustain growth in a competitive business environment (Deloitte, 2021). Nevertheless, business need technology as an enabler to help them adopt to change and digitally transform their organization in the years to come. Connecting employee experience with the business plays a big role in increasing productivity and growing businesses (IBM Smarter Work Institute, 2018). 
As noted in the work of Jacob Morgan (2017), employee experience encompasses all interactions between and organization and an employee. Today, happiness, productivity and health of the entire workforce have become the major focus of HR leadership (KPMG, 2020). For this reason, we find that organizations are now inclined to redefine the employee experience and are spending significant resources to support employees especially during the pandemic. Organizations have understood that the employee journey starts with experiences that are carried over throughout their lifecycle and influence their productivity. Personal connection and commitment is an important aspect for employees and there is a need for organizations to amplify the experiences to be competitive (Gobe, 2001). Additionally, for the same organizations to thrive, technology is the foundation in managing the new way of work as well as improving the employee experience. Technology is a key driver in the new way of work where remote working has become the norm (IDC, 2019).

The paper reviews recommendations that will provide a solid basis for organizations to understand the employee experience imperative and serve as an opportunity to improve their performance with the existing workforce especially during the pandemic (Deloitte, 2020). With the ongoing crisis today, organizations will need to make a fundamental shift on their operations and focus on the following employee related topics to ensure business continuity and performance.

- Talent Attraction and Retention

- Employee Productivity and Engagement

- Employee Health and Well-being

The future of organizations is at the intersection of digital transformation and people's influence. HR leaders need to embrace new strategies and more agile ways of working to improve the employee experience. To improve the employee experience, there is a need for companies to create moments that matter (Haris, 2007). This is because it is such peak moments in an employee lifecycle will dominate their memory of the experience within the organization and in turn have an impact on performance (IBM Smarter Work Institute, 2018).

\section{How Organizations Can Redefine Employee Experience}

\subsection{Talent Attraction}

In the context of the pandemic, organizations have had to continuously change their operating models while ensuring business continuity. To thrive in the new norm, effective companies will have to have resources to reassess how they work on reasoning more dynamically, with a greater perspective on their talent procurement strategy. How can they acquire skills within a short time? The need for realignment of talent to fill critical roles that didn't exist before the pandemic is greater. Additionally, technology has become a constant remobilizing resources as businesses had to offer new products and services. With the introduction of remote working, organizations have used the open talent market to help address 
the skill shortage and acquire skills that will match the new business priorities (Deloitte, 2020).

In such a short period, businesses worldwide have accomplished high levels of remote work, which would have taken months to introduce under "normal" conditions. More than ever, organizations have realized that technology is key in support talent acquisition and in flexible work arrangements. Especially for the talent that is spread across the globe. Also, contingent workforce has become vital in filling up critical roles and helping the organization recover faster and at an optimal cost. As the workplace has become digital, organizations are realizing the importance of technology not only to acquire talent but also to deliver and respond with agility and efficiency. Every business transformation requires talent and technology. With the pandemic, companies have been forced to accelerate transformation and use of technology.

\subsection{Employee Productivity and Engagement}

Every organization has gone through challenges of acquiring the right talent and at the right time today. According to a Technology Skills Survey by IDC (2019), there has been an increased need of training and lack of the right skills has led to the delays in the introductions of products and services in the market. Identifying skill gaps and continuously working on closing them, is one of the most crucial areas when it comes to productivity and engagement. Employees are engaged when they get an opportunity to upskill and develop themselves. In turn, it converts to great performance from the employee side and a competitive advantage for the organization. For this reason, implementing agile and mobile learning and development platforms will be vital for organizations keen on meeting the upskilling needs of their talent.

Companies need to have an outstanding workplace that values productivity and engagement by providing the necessary technology to support their tasks. As organizations continue to face uncertainty, its crucial to acknowledge that employees are the most critical element for long-term success. In times of hardship, employers must help workers, maintain high skills, and guarantee job protection. Additionally, it is important for business sustainability and the recognition of prospects in moments of emergency to have resources in place. To maintain business sustainability, companies would have to develop a strong team, while finding exciting challenges and introducing viable strategies to help meet business goals (Sharma, 2019).

According to Morgan (2017), companies who heavily invest in improving employee engagement and experiences, were listed as the best place to work and in general had returns of more than four times the average profit and two times the average revenues. To engage the workforce and benefit from that engagement, there is need to prioritize and invest in employee experience. As Plaskoff once said, "the employee journey has many milestones and interactions, and the quality of employee experience has a direct influence on employee satisfaction, 
engagement, commitment and, in the end, performance" (Plaskoff, 2017: p. 141).

\subsection{Employee Health and Well-Being}

Looking back over the last one and half year, mental health has become a topic that organizations can no longer afford to ignore. The crisis has affected individuals in different ways and led to the suggestion that people were going through elevated levels of stress and anxiety across the globe. Physical distancing and quarantine measures implemented were a huge contributor to the mental health since the pandemic begun (Moukaddam, 2020). Today, a company's spend on employee and health matters has risen annually by $5 \%$ in the recent years according to IDC Report (2019). As part of improving employee experience, major companies are now investing in managing the health of their workforce. Consquently, they are able to improve their brand and can be viewed as employer of choice. For people returning to work, employees will be faced with new challenges that will have an impact on the physical and mental well-being that in turn impact the business' bottom line. To address such concerns, organizations are implementing tools to collect information and data on the employee experiences and understand what they need as they continue working remotely. Additionally, organizations are considering the introduction of new working initiatives. For example: flex time, remote/onsite/hybrid working and providing access to mental health care.

Fostering a culture that invests on employee experiences contributes to sustained growth for any business today. Leaders can support the organization by monitoring the wellbeing of their employees through technology, effective communication, and empathy.

\section{Conclusion}

With the Pandemic here to stay, organizations need to adapt to meet the demands of their customers and employees. If employees are not engaged, then performance will be low and customers' dissatisfaction may shoot. For this reason, employee experience needs to at the top of the list for any organization looking at growth and increasing competitive advantage. The three examples of redefining experience paint a picture of how HR can redefine their current employee experiences to adapt to change today. Investing in people by continuously listening and addressing their challenges is a key ingredient in achieving success. The purpose of this paper was highlighting the importance of focusing on employee experience and how organizations can implement simple initiatives to increase productivity and engagement and drive business outcomes.

\section{Conflicts of Interest}

The author declares no conflicts of interest regarding the publication of this paper. 


\section{References}

Deloitte (2020). Adaptable Organization: The New Normal. Deloitte India LLP.

Deloitte (2021). Enterprise Adaptability Designing Resilient Organizations. Deloitte Development LLC.

Gobe, M. (2001). Emotional Branding: The New Paradigm for Connecting Brands to People. New York: Allworth Press.

Haris, P. (2007). We the People: The Importance of Employees in the Process of Building Customer Experience. Journal of Brand Management, 15, 102-114. https://doi.org/10.1057/palgrave.bm.2550123

IBM Smarter Work Institute (2018). The Financial Impact of a Positive Employee Experience. IBM. Last modified 2018. https://www.ibm.com/downloads/cas/XEY1K26O

IDC (2019). High-Tech Skills. Luxembourg: Publications Office of the European Union.

KPMG (2020). The Importance of Workforce Transformation in a COVID-19 World. KPMG LLP.

https://assets.kpmg/content/dam/kpmg/sa/pdf/2020/the-importance-of-workforce-tran sformation-during-covid-19.pdf

Morgan, J. (2017). The Employee Experience Advantage: How to Win the War for Talent by Giving Employees the Workspaces they Want, the Tools They Need, and a Culture They Can Celebrate. Hoboken: John Wiley \& Sons.

Moukaddam, N. (2020). Psychiatrists Beware! The Impact of COVID-19 and Pandemics on Mental Health. Psychiatric Times, 37.

Plaskoff, J. (2017). Employee Experience: the New Human Resource Management Approach. Strategic HR Review, 16, 136-141. https://doi.org/10.1108/SHR-12-2016-0108

Sharma, N. (2019). P-O Fit and Employee's Turnover Intentions: Examining the Mediation of Employee Engagement in Indian IT Sector. International Journal of Human Capital and Information Technology Professionals, 10, 51-60.

https://doi.org/10.4018/IJHCITP.2019040104 